\title{
EFFECT OF RELATIVE HUMIDITY ON EVAPORATION RATES IN NABATIEH REGION
}

\author{
Nasser Farhat \\ The Doctoral School of Literature, Humanities and Social Sciences, Department of Geography, Beirut, Lebanon.
}

(Received 12 January 2018 - Accepted 23 January 2018)

\begin{abstract}
Farhat, Nasser. 2018. Effect of relative humidity on evaporation rates in Nabatieh region. Lebanese Science Journal, 19(1): 59-66.

Relative humidity affects evaporation, which is in turn is affected by several climatic parameters. This effect is on the increase as a result of climate changes, especially increased temperature. Nabatiyeh region, in south Lebanon, was selected for this study, even though comprehensive climate records are not available. Instead, data from an experimental meteorological station capable of providing all climatic parameters digitally, which includes an evaporation basin of the form A, was used. This study provided explanations of the general climate in the study area. This includes average annual temperature, precipitation and evaporation. Factors affecting relative humidity were determined. It was found that the evaporation values changed by the changing direction of the prevailing wind, and fluctuating higher values were recorded in autumn, due to the south-eastern dry winds, which lead to a fluctuation in the amount of daily evaporation. An inverse relationship between relative humidity and evaporation was observed, with significant correlation between them. The net effect of relative humidity on evaporation was investigated in this study by comparing data in two days in which the values of other climatic factors affecting evaporation were the same. It was found that the amount of daily evaporation increased by $80 \%$ when the relative humidity declined to $53 \%$. Most likely, in the coming years, the region is moving towards more water stress in light of changes in climatic parameters.
\end{abstract}

Keywords: Wind, evaporation, relative humidity, pressure, temperature.

\section{INTRODUCTION}

Located along the Eastern Mediterranean, Lebanon is mainly influenced by the Mediterranean climate. It is an eclectic climate between the moderate cold temperate zones, and Desert sub-tropical regions. Lebanon is exposed to several types of wind because of its rugged topography, and the western winds prevail most of the year. The passage of these winds over the Mediterranean makes them moist. This leads to a mild weather in summer and rain in the winter, due to the arrival of cold air masses to the eastern basin of the Mediterranean Sea. Lebanon is also affected by the south-eastern dusty winds or "the so-called Khamassin", which arises over the Libyan and Egyptian desert in the spring and autumn. These winds are hot and dry winds which reduces atmospheric moisture. They mostly affect southern Lebanon, and Nabatiyeh province in particular, which is the study area (Figure 1).

Relative humidity is affected by wind direction blowing on the study area. The western wind is moist and the eastern wind is dry, thus the change in daily evaporation rate was studied considering the change in relative humidity when other climatic factors were stable. Evaporation has an obvious impact on water resources, but it also decreases water available for agricultural and domestic uses in the region. The agricultural use is estimated at 12 million $\mathrm{m}^{3}$ per year (Ministry of Agriculture, 2012), and the domestic consumption of 170-200 liters/capita/year (Comair, 2005). 


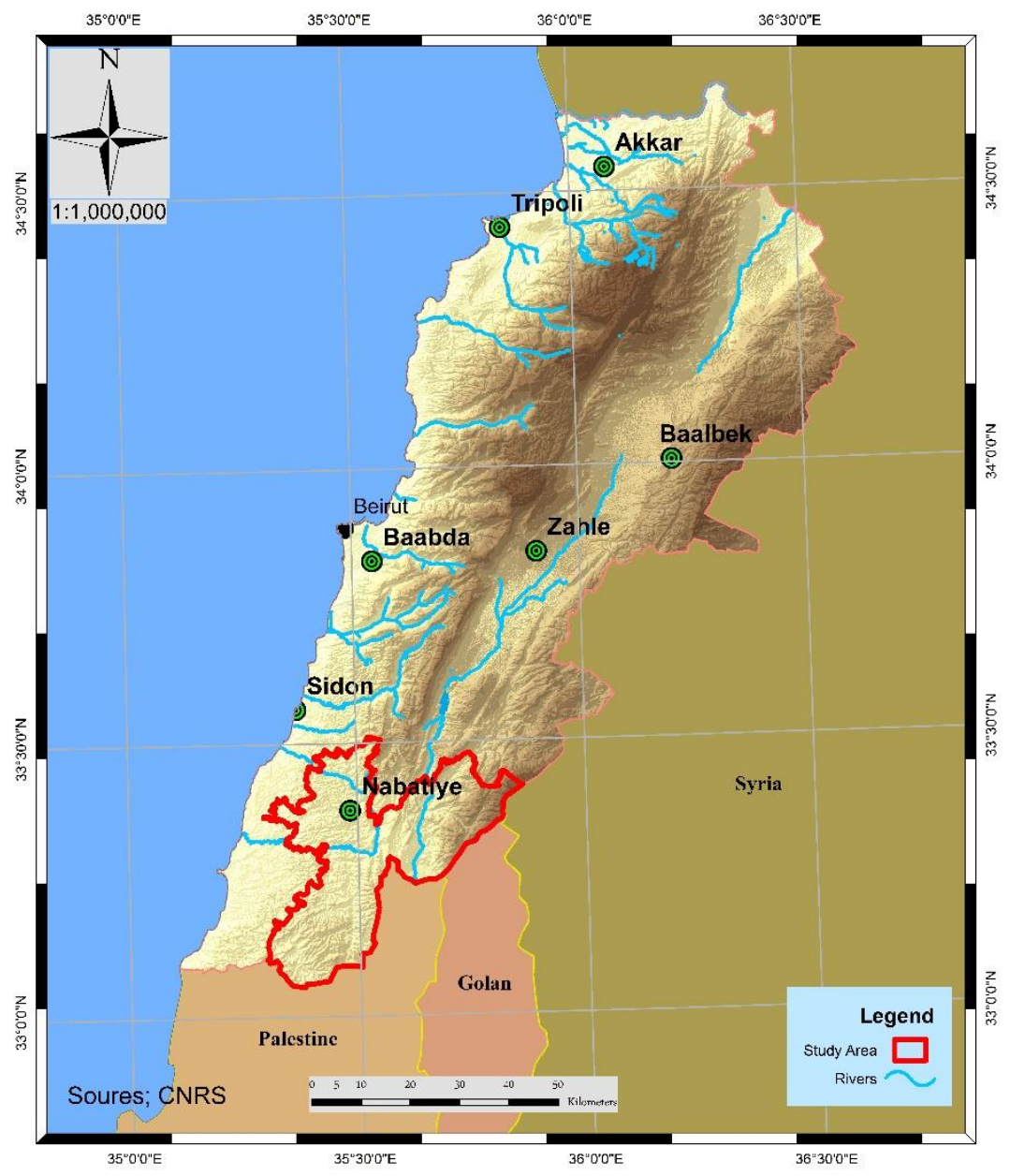

Figure 1. Map showing the location of the study area.

\section{Concepts}

\section{Evaporation rate}

Water is transported from the surface of the earth into the atmosphere by two distinct mechanisms: evaporation and transpiration (Plate, 1982). Evaporation can be defined as the process where liquid water is transformed into a gaseous state. Transpiration is the process of water loss from plants through stomata, and estimating its rate require the availability of special instruments (Singh, 1992). The volume of total evaporation in Lebanon is estimated at 50\% (including transpiration) of the volume of precipitation (Fawaz, 2007), and in the study area was estimated at around $43 \%$ of the annual volume of precipitation (Farhat, 2017).

The area of Nabatieh Region is around $1142 \mathrm{~km}^{2}$. It receives an annual precipitation of around $850 \mathrm{~mm}$ (Lebanon Climate Atlas, 1977; Meteorological Department, 2017). Therefore the annual precipitation volume in this region is about 970 million $\mathrm{m}^{3}$. There are no indicators for a radical change in this volume (Traboulsi, 2012c). The annual evaporation volume is estimated at 415 million $\mathrm{m}^{3}$. Evaporation values are likely to rise due to climate change and high temperatures (Traboulsi, 2014). 
Several climatic factors govern the volume of evaporation, and perhaps the most important is temperature. The average daily mean temperature in the Nabatieh region ranges between $7{ }^{\circ} \mathrm{C}$ and $28{ }^{\circ} \mathrm{C}$, and the annual average is between $15^{\circ} \mathrm{C}$ and $20^{\circ} \mathrm{C}$ (Figure 2).

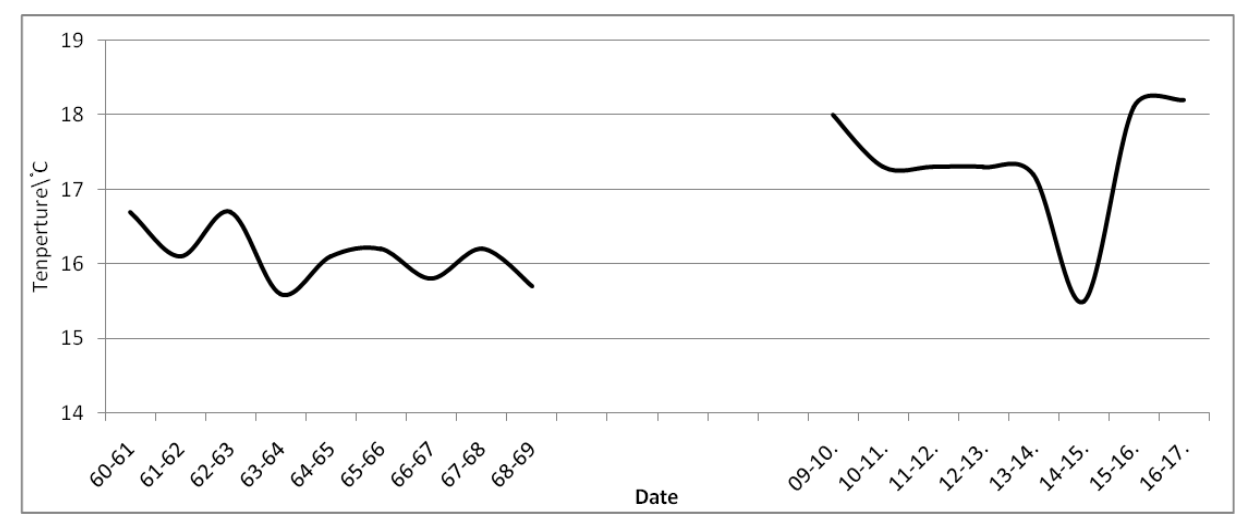

Figure 2. The average temperature mean in Marjayoun station 1960-1969 and 2009-2017.

Areas near the coast do not have temperatures below $5{ }^{\circ} \mathrm{C}$, and it exceeds the threshold of $35{ }^{\circ} \mathrm{C}$ on some summer days of the year. As for the interior region, winter temperatures fall below zero Celsius in a number of days of the year, especially those located on the slopes of Mount Hermoun (Jabal Al-Sheikh). In contrast, temperatures do not exceed $30{ }^{\circ} \mathrm{C}$ in summer.

\section{Relative Humidity}

The relative humidity in the study area ranges from 50\% to $85 \%$ most of the days of the year (Lebanon Climate Atlas 1977; Meteorological Department, 2017). However, during the spring and autumn transition, the area is exposed to dry oriental winds and humidity decreases to below $15 \%$, a period of up to 50 intermittent days. This in turn would increase daily evaporation to levels higher than normal. It also requires that the humidity of the atmosphere is less than the evaporating surface (at $100 \%$ relative humidity there is no more evaporation) (Hess, 1959).

\section{MATERIALS AND METHODS}

\section{Data Availability}

Lebanon lacks comprehensive long-term climatic data. In Nabatieh region, there is only one meteorological station located in Marjayoun, where the available climate data is intermittent due to the security conditions in the region. Available data cover the period from 1961 to 1975 and from 2009 to 2017. These data are available at the Lebanon Climate Atlas of 1977, and with the General Directorate of Civil Aviation at Beirut International Airport, Meteorological Department.

In addition, climatic data is also provided by the Lebanese Agriculture Research Institute (LARI, 2012) with data on the South region from 1959 to1973 and from 2012, and the data provided by the National Council for Scientific Research (CNRS-L), which was retrieved by remote sensing.

\section{Tools for Data Support}

Studying the relationship between relative humidity and evaporation needs hourly measures, and thus the relationship will be determined by changing the value of one of the two elements. A sophisticated experimental digital weather station has been installed (Figure3) in Nabatieh region at the following geographic coordinates: $35^{\circ} 29^{\prime} 00^{\prime \prime} \mathrm{E}$ 
and $33^{\circ} 23^{\prime} 00^{\prime \prime} \mathrm{N}$, which enabled to retrieve reliable data used for this study. The station can record data for several climatic factors (temperature, relative pressure, absolute pressure, rain, relative humidity, wind speed and direction, gust, dew point, wind chill, tendency) every five minutes, and sends them wirelessly to a special panel connected to the computer.

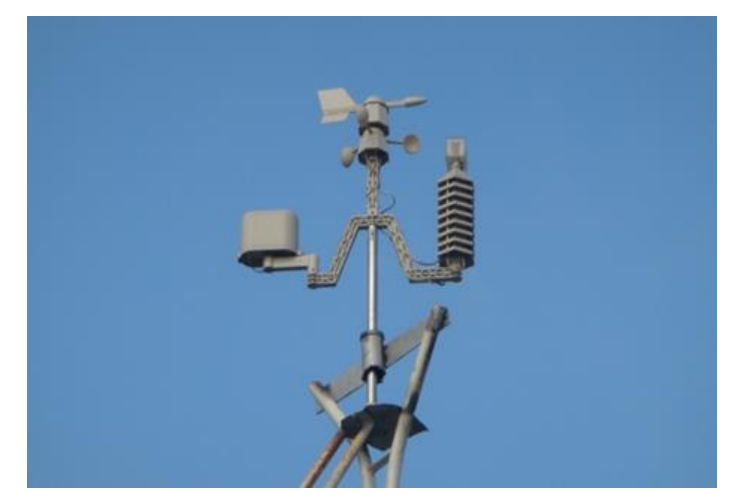

Figure 3: The used weather station.

Therefore, it is useful to study the relationship of two climatic factors with no change in the other climatic factors; especially those that directly affect evaporation and relative humidity, such as temperature and wind speed.

The selected time period for investigation was autumn 2017, specifically the months between September and December. During these four months, the private meteorological station recorded 35,136 values for each climatic factor.

Evaporation pan of model A, was set up beside the special experimental weather station. It is a cylindrical basin with a diameter of 1.207 meters, and a height of 0.255 meters (Figure 4), placed on a wooden base $5 \mathrm{~cm}$ above ground, to permit air to pass through it. The pan had an evaporation coefficient of about 0.75 , due to its mineral nature which is affected by temperature, leading to a rise in the amount of evaporation.

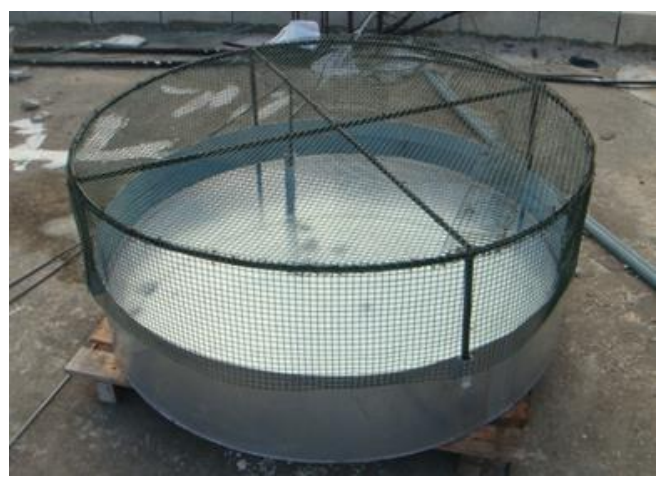

Figure 4: The evaporation pan. 


\section{RESULTS AND DISCUSSION}

\section{Prevailing wind and evaporation}

Four months data was analyzed at the private meteorological station and the evaporation pan, in order to monitor the effect of relative humidity on daily evaporation. Such influence often showed during this time period, because of the dry east wind gusts on the study area as mentioned above. The proportion of dry winds in the four months was about $48 \%$, as compared to $43 \%$ of Western and Northwestern winds (Figure 5). This oscillation makes relative humidity and evaporation in a state of daily instability. Note that the prevailing wind direction throughout the year at the location of the used station was the western and north-west (Figure 6).

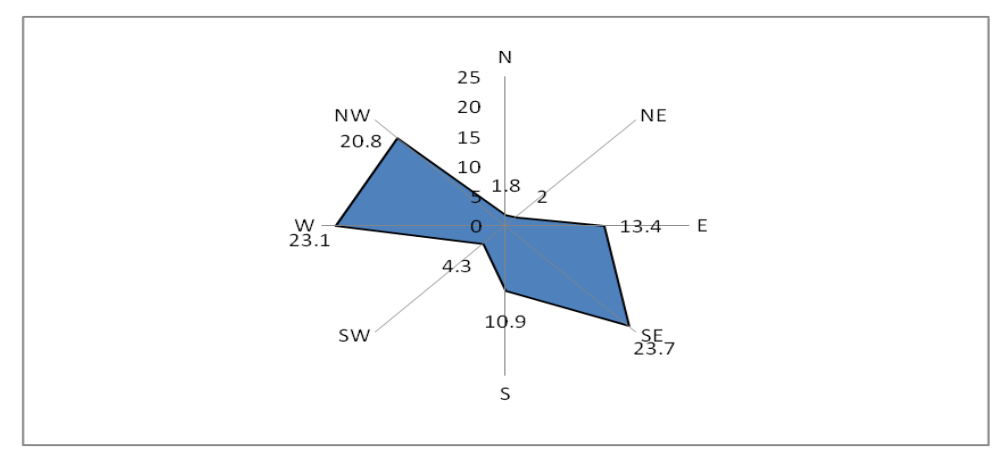

Figure 5: Prevailing wind direction during the four months.

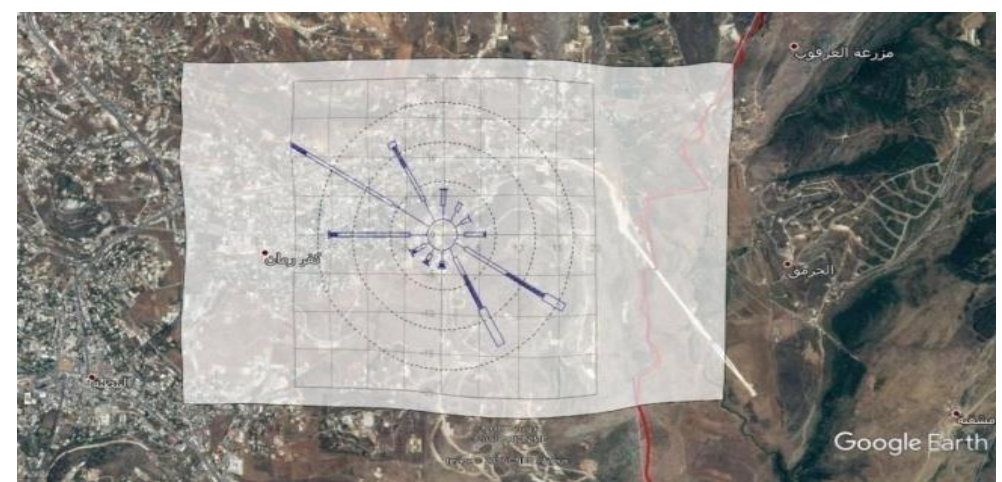

Figure 6: The general wind rose at the station's place.

Therefore, during the autumn the study area was dominated by volatile winds, there was a large fluctuation in the volume of evaporated water dictated by the prevailing humidity. Figure 7 summarize the data obtained. The magnitude of the difference in the amount of evaporation between the peak day and the following day is shown. 


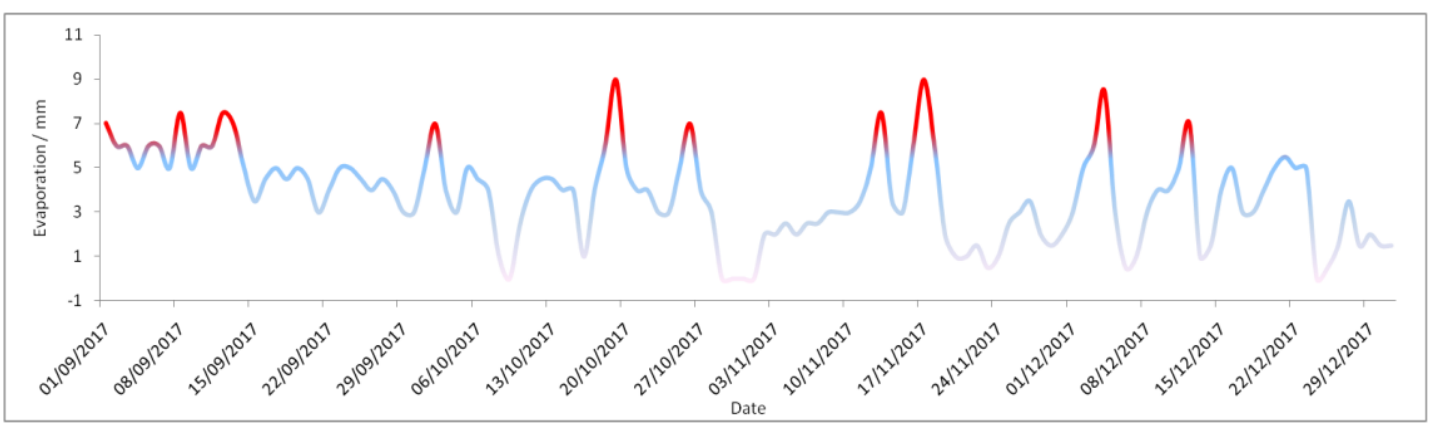

Figure 7: Evaporation rate during the four months (September-December, 2017).

This is a typical fluctuating Mediterranean climate system during this period of the year, as evidenced from the data from the evaporation basin. Highest evaporation level was noticed on 17\11 2017), whereas evaporation value was very much decreased on $15 \backslash 11 \backslash 2017$, only two to three days earlier (Table 1), although temperature did not change radically (only $3.9^{\circ} \mathrm{C}$ ).

Table 1. Values of climatic factors during five consecutive days.

\begin{tabular}{|l|l|l|l|l|l|l|}
\hline Date & $\begin{array}{l}\text { Evaporation } \\
(\mathrm{mm})\end{array}$ & $\begin{array}{l}\text { Relative } \\
\text { Humidity }(\%)\end{array}$ & $\begin{array}{l}\text { Temperatures } \\
\left({ }^{\circ} \mathrm{c}\right)\end{array}$ & $\begin{array}{l}\text { Wind } \\
(\mathrm{m} / \mathrm{s})\end{array}$ & $\begin{array}{l}\text { Atmospheric } \\
\text { pressure (hpa) }\end{array}$ & Wind direction \\
\hline $15 / 11 / 2017$ & 3 & 52.3 & 18.2 & 2.2 & 957 & W, NW \\
\hline $16 / 11 / 2017$ & 6 & 32.8 & 21.1 & 3.1 & 956 & S, SE \\
\hline $17 / 11 / 2017$ & 9 & 26.4 & 22.1 & 3.6 & 954 & S, SE, E \\
\hline $18 / 11 / 2017$ & 6 & 29.9 & 21.8 & 3.3 & 953 & SE, S \\
\hline $19 / 11 / 2017$ & 2 & 75.1 & 17.2 & 2.3 & 955 & NW, W \\
\hline
\end{tabular}

The relationship between relative humidity and evaporation was an inverse relationship (Figure 8). This is shown by the average daily relative humidity values in the investigated station, and the values of daily evaporation in the evaporation pan. It can be concluded that the more decrease in the value of the relative humidity, the higher the daily evaporation (Figure 8). Where the highest daily evaporation value was recorded on 17/11/2017 by $9 \mathrm{~mm}$, relative humidity recorded its lowest value on the same date.

In contrast, the lowest value of daily evaporation, which is about $0.1 \mathrm{~mm}$, compared to the highest relative humidity value of $99 \%$ was on $24 / 12 / 2017$.

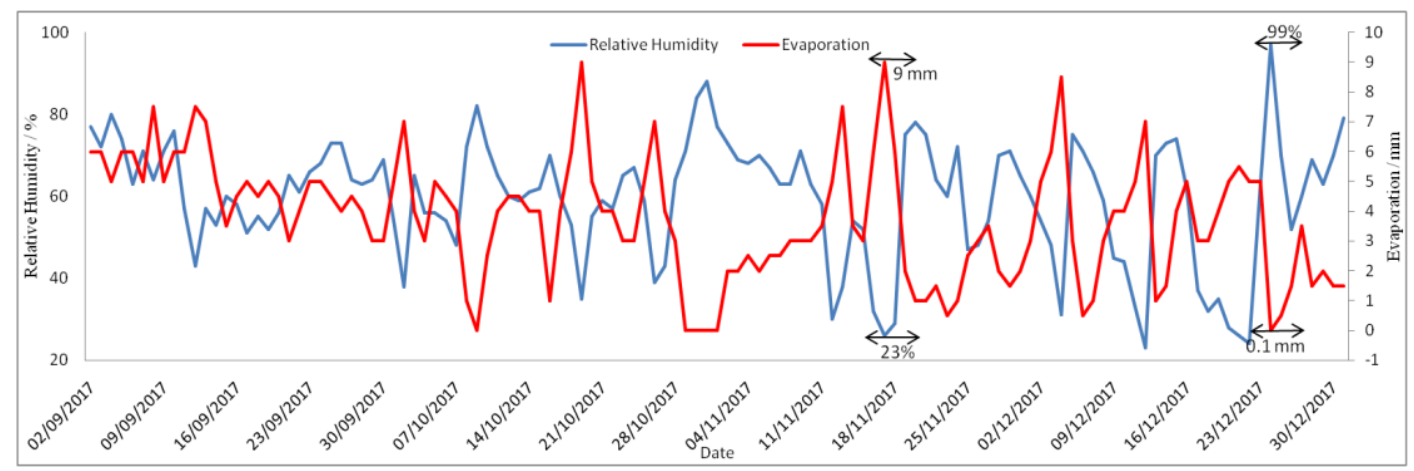

Figure 8: Variation of the relationship between relative humidity and evaporation. 
To determine the relationship between relative humidity and evaporation, we resorted to calculating the correlation coefficient between them, during four months as shown in Figure 9.

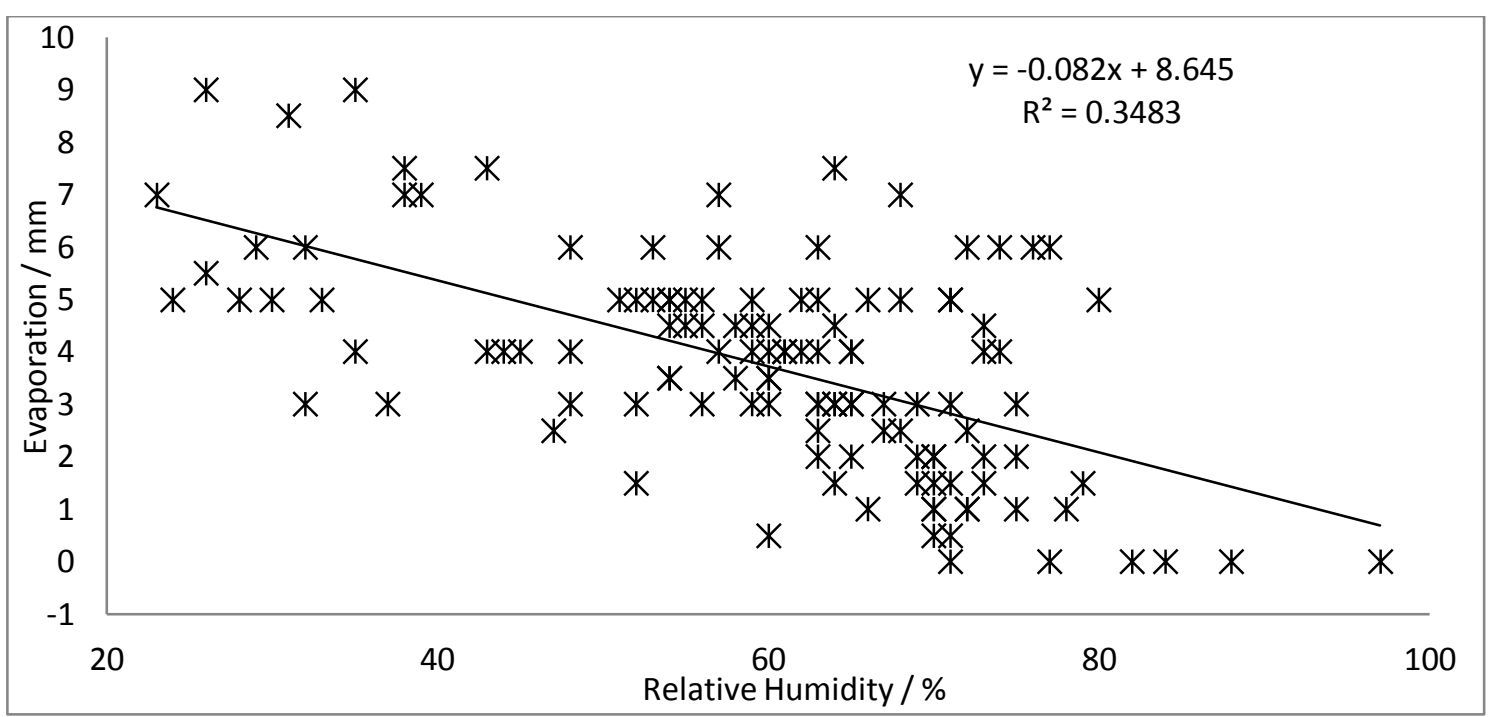

Figure 9: Evaporation correlation with relative humidity.

The correlation coefficient obtained indicated that the relative humidity explain $34.8 \%$ of the variance, and this ratio is considered too high in light of other climatic variables, which in turn directly affect the daily evaporation values.

\section{Quantitative influence of relative humidity on daily evaporation}

The climatic factors is influential and effective in determining the daily evaporation rate, since they are linked to each other with varying relationships, both directly and indirectly (Ceyhan, 2013). However, the impact of one of them stands out more than others in the light of their values within a limited regime, as shown in Table 1, during five consecutive days.

In the study area, the atmospheric pressure ranged between 953 and $957 \mathrm{hpa}$, wind speed ranged between 2.2 $\mathrm{m} / \mathrm{s}$ and $3.6 \mathrm{~m} / \mathrm{s}$, temperatures ranged from 17.2 to $22.1^{\circ} \mathrm{C}$. Only relative humidity had a large difference between the lowest and the maximum values, which ranged between $26.4 \%$ and $75.1 \%$. This had a great effect on the volume of evaporation during the five days period from 2 to $9 \mathrm{~mm}$.

The effect of relative humidity on evaporation on 1/10/2017, and 17/11/2017 was investigated, in light of similar values of all other climatic factors. The temperatures on both days were equal to $22.4{ }^{\circ} \mathrm{C}$, and wind speed at the level of [3.5-3.6] m/s, and atmospheric pressure at 954-955 hpa, as well as a clear sky in both days. However, the recorded relative humidity value was $57 \%$ for the date of $1 / 10 / 2017$ and $26.4 \%$ for $11 / 17 / 2017$. In contrast, the evaporation value was $5 \mathrm{~mm}$ for the date 1/10/2017 and $9 \mathrm{~mm}$ for the date 17/11/2017 (Figure 10). 


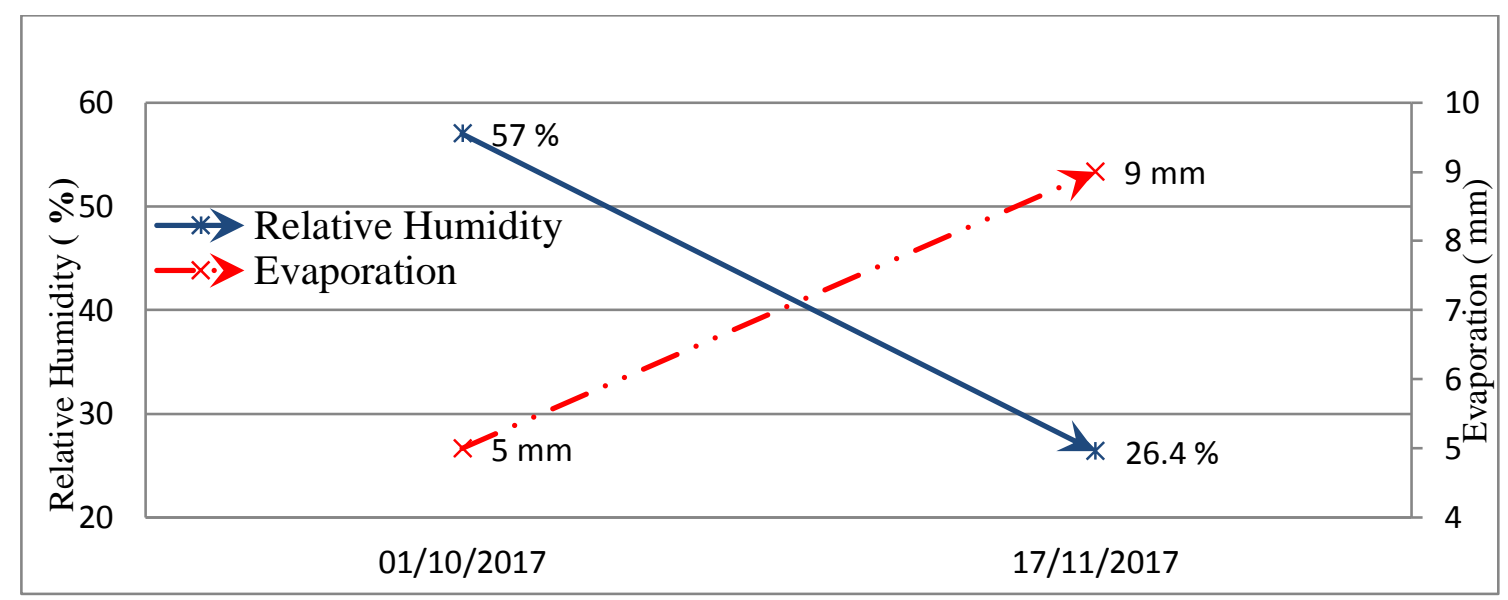

Figure 10. Atmospheric pressure 954-955 hpa, wind 3.5-3.6 m/s, temperature 22.4 C.

Daily evaporation was increased from 5 to $9 \mathrm{~mm}$ during the two days, a difference of $4 \mathrm{~mm}$, this means that the volume of daily evaporation increased by $80 \%$ and this rate is very high if compared with a decrease in relative humidity from $57 \%$ to $26.4 \%$. This means there was a drop of $54 \%$ in relative humidity when the values of all other climatic factors were unaffected.

In conclusion, this study showed that relative humidity has a direct and significant effect on water evaporation. This is reflected on the various ecosystems in the study area; especially water resources and vegetation cover. Whereas, the high value of daily evaporation led to an increase in agricultural consumption of water resources, the same applies to domestic water consumption, in addition to the increased volume of water lost from water surfaces. This adds burden and risk to the environment, and increases the risk of water scarcity and desertification of agricultural areas, and it contributes to the elimination of vegetation through the outbreak of fires during the dry east wind period.

\section{REFERENCES}

(CAL) Atlas climatique du Liban: 1977, Tome 1.3.

Ceyhan I. 2013. Investigation of the Relationship Between Atmospheric Pressure and Evaporation, Undergraduate Thesis, Istanbul Technical University, Turkey, (In Turkish). $17 \mathrm{pp}$.

Comair, F. 2005. Water of Lebanon between the loss and investment. 305 pp.

Farhat N. 2017. Water Resources and Population Growth in Nabatieh Governorate. 326 pp.

Fawaz, M. 2007. Towards Water Policy in Lebanon, Institute of Higher Engineering in Beirut (in Arabic). ??pp.

Hess S. H. 1959. Introduction to the oretical meteorology. Holt, Rinehard Winston, New York. 257 pp.

Ministry of Public Transport (MoPT), General Directorate of Civil Aviation at Beirut International Airport, Meteorological Department. Report on annual precipitation for 2017, 2 pp.

Ministry of Agriculture (MoA), Food and Agriculture Organization of the United Nations (FAO), and Italian Cooperation Office. 2012. General Results of the Comprehensive Agricultural Statistics 2010, National Observatory for Agricultural Development Project, Lebanon. 43 pp.

National Council for Scientific Research (CNRS-L). 2016. Digital data For Arc GIS.

Plate E. 1982. Engineering Meteorology. Elsevier Scientific Publishing Company, Amsterdam. 72 pp.

Singh R., Bishnoi, O. P. and Ram, N. 1992. Relationship between evaporation from class 'A' open pan evaporimeter and meteorological parameters at Hisar. Haryana Agri Univ. J. Res., 22(2): 97-98.

Traboulsi M., 2012c : La saison pluvieuse au Proche-Orient : une tendance au racourcissement. Climatologie, Revue de l'Association Internationale de Climatologie, 9: 9-29.

Traboulsi, M. 2014. Les fortes chaleurs au Proche-Orient et leurs relations avec la circulation atmosphérique régionale. Etude des tendances, indicatrices des changements climatiques. HANNON, 27: 19 pp. 